\title{
Editorial to the special issue: Recent advances in Computational Mechanics and Innovative Materials, in honor of Professor J.N. Reddy for his 75th birthday
}

\author{
Glaucio H. Paulino • Elio Sacco
}

Accepted: 6 April 2021 / Published online: 19 April 2021

(C) Springer Nature B.V. 2021

This special issue of Meccanica celebrates the 75th birthday of Prof. J.N. Reddy. His professional work and warm personality have greatly inspired a generation of researchers in the broad field of applied mechanics. He made significant contributions to the field through his remarkable output of research papers and widely used textbooks on linear and nonlinear finite element analysis, variational methods, composite materials and structures, applied functional analysis, and continuum mechanics. His writings have also had a major impact on engineering education and led to technological advances around the world.

With this special issue of Meccanica, we celebrate Prof. Reddy's birthday with a thematic focus on "Computational Mechanics and Innovative Materials," which encompasses the large spectrum of scientific topics to which Prof. Reddy has contributed and inspired new research ideas. Many of his friends and collaborators contributed to the present special issue.

G. H. Paulino ( $\square)$

School of Civil and Environmental Engineering, Georgia Institute of Technology, Atlanta, USA

e-mail:paulino@gatech.edu

\section{E. Sacco}

Dipartimento di Strutture per l'Ingegneria e l'Architettura, University of Naples Federico II, Napoli, Italy

e-mail: elio.sacco@unina.it
The topics of the special issue span from solids \& fluids to statics \& dynamics to classical \& nonclassical continuum mechanics to linear and nonlinear analysis to related topics such as phase-field, constitutive modeling, origami mechanics, biomechanics, novel numerical methods, material design, and optimization. The papers are organized into 5 nonunique groups: (1) papers co-authored by Prof. Reddy and related work; (2) novel numerical methods; (3) multiphysics; (4) composites; and (5) interdisciplinary. Each of the nineteen papers are briefly outlined below according to the aforementioned categories.

The first two papers are co-authored by Prof. Reddy himself [1, 2]. Raghu et al. [1] present a phase-field model for fracture of thick plates under dynamic loads. Romanoff et al. [2] investigate post-buckling of webcore sandwich plates based on classical continuum and point out the need for non-classical continuum mechanics, which is a topic addressed by a few other authors. For instance, Romano and Diaco [3] present a theoretical account of nonlocal problems in elasticity. Pinnola et al. [4] use a nonlocal approach to model damped small-scale beams. Surana and Carranza [5] demonstrate the influence of internal rotations on the dynamic response of solid continua. In connection with the phase-field method [1], Bijaya and Chowdhury [6] address fracture problems considering finite strains. 
The next group of papers addresses novel numerical methods in computational mechanics including the variational multiscale method (VMS) for incompressible flows by Kang and Masud [7], the virtual element method (VEM) for nearly incompressible materials by Park et al. [8], the generalized finite element method (GFEM) for fracture of composites by Alves et al. [9], and the Carrera Unified Formulation (CUF) for stress analysis by Filippi and Carrera [10].

On the multiphysics front, the contributions include visco-poroelastic formulation for gels by $\mathrm{He}$ and $\mathrm{Hu}$ [11], constitutive response of dielectric elastomers by Ghosh and Lopez-Pamies [12], and chemo-mechanical modeling of solid-state batteries by Bistri et al. [13].

With regard to composite materials, the research includes determining stacking sequences in composite laminates through the integrated design optimization approach by Cutolo et al. [14], and the two-step Bayesian framework for estimating effective elastic constants of single plies within a multi-laminate polymer matrix composite by Castillo and Kalidindi [15].

Finally, the interdisciplinary group of papers includes post-bucking analysis of elasto-plastic framed structures and curved structures by Yang et al. [16], study of curved creases as a means to redistribute global bending stiffness in corrugations by Woodruff and Filipov [17], investigation of the response of cells on a bed of micro-posts idealized as a Winkler foundation using a homeostatic mechanics framework by Vigliotti et al. [18], and coarsegraining for polymeric metamaterial design by Varma and Sarkar [19].

As Prof. Reddy's books have motivated research in their topical areas, it is our hope that the work presented here will serve as a source of inspiration for further advancements in computational mechanics and innovative materials.

\section{References}

1. Raghu P, Rajagopal A, Jalan SK, Reddy JN (2021) Modeling of brittle fracture in thick plates subjected to transient dynamic loads using a hybrid phase field model. Meccanica. https://doi.org/10.1007/s11012-020-01224-z

2. Romanoff J, Jelovica J, Reddy JN, Remes H (2021) Postbuckling of web-core sandwich plates based on classical continuum mechanics - success and needs for non-classical formulations. Meccanica. https://doi.org/10.1007/s11012020-01174-6

3. Romano G, Diaco M (2021) On formulation of nonlocal elasticity problems. Meccanica. https://doi.org/10.1007/ s11012-020-01183-5

4. Pinnola FP, Vaccaro MS, Barretta R, de Sciarra FM (2021) Random vibrations of stress-driven nonlocal beams with external damping. Meccanica. https://doi.org/10.1007/ s11012-020-01181-7

5. Surana KS, Carranza CH (2021) Dynamic behavior of thermoelastic solid continua using mathematical model derived based on non-classical continuum mechanics with internal rotations. Meccanica. https://doi.org/10.1007/ s11012-020-01221-2

6. Bijaya A, Chowdhury SR (2021) On failure mode transition: a phase field assisted non-equilibrium thermodynamics model for ductile and brittle fracture at finite strain. Meccanica. https://doi.org/10.1007/s11012-020-01175-5

7. Kang S, Masud A (2021) A variational multiscale method with immersed boundary conditions for incompressible flows. Meccanica. https://doi.org/10.1007/s11012-02001227-w

8. Park K, Chi H, Paulino GH (2021) B-bar virtual element method for nearly incompressible and compressible materials. Meccanica. https://doi.org/10.1007/s11012-02001218-x

9. Alves PD, Simone A, Duarte CA (2021) A generalized finite element method for three-dimensional static fractures in fiber-reinforced Composites. Meccanica. https://doi.org/10. 1007/s11012-020-01211-4

10. Filippi M, Carrera E (2021) Stress analyses of viscoelastic three-dimensional beam-like structures with low- and highorder one-dimensional finite elements. Meccanica. https:// doi.org/10.1007/s11012-020-01191-5

11. He D, Hu Y (2021) A nonlinear visco-poroelasticity model for transversely isotropic gels. Meccanica. https://doi.org/ 10.1007/s11012-020-01219-w

12. Ghosh K, Lopez-Pamies O (2021) On the two-potential constitutive modeling of dielectric Elastomers. Meccanica. https://doi.org/10.1007/s11012-020-01179-1

13. Bistri D, Afshar A, Di Leo CV (2021) Modeling the chemomechanical behavior of all-solid-state batteries: a review. Meccanica. https://doi.org/10.1007/s11012-020-01209-y

14. Cutolo A, Carotenuto AR, Palumbo S, Esposito L, Minutolo V, Fraldi M, Ruocco E (2021) Stacking sequences in composite laminates through design optimization. Meccanica. https://doi.org/10.1007/s11012-020-01233-y

15. Castillo AR, Kalidindi SR (2021) Bayesian estimation of single ply anisotropic elastic constants from spherical indentations on multi-laminate polymer-matrix fiber-reinforced composite samples. Meccanica. https://doi.org/10. 1007/s11012-020-01154-w

16. Yang YB, Chen A, He S (2021) Research on nonlinear, postbuckling and elasto-plastic analyses of framed structures and curved beams. Meccanica. https://doi.org/10. 1007/s11012-020-01182-6

17. Woodruff SR, Filipov ET (2021) Curved creases redistribute global bending stiffness in corrugations: theory and experimentation. Meccanica. https://doi.org/10.1007/ s11012-020-01200-7 
18. Vigliotti A, Shishvan SS, McMeeking RM, Deshpande VS (2021) Response of cells on a dense array of micro-posts. Meccanica. https://doi.org/10.1007/s11012-020-01208-z

19. Varma TV, Sarkar S (2021) Designing polymer metamaterial for protective armor: a coarse-grained formulation. Meccanica. https://doi.org/10.1007/s11012-020-01201-6
Publisher's Note Springer Nature remains neutral with regard to jurisdictional claims in published maps and institutional affiliations. 